\title{
A Bulldog of Your Owen: The Philosophies Behind the Huxley-Owen Debate
}

\author{
Owen's Ape and Darwin's Bulldog: Beyond Darwinism and Creationism, \\ by Christopher E. Cosans. Indiana University Press: \\ Bloomington, 2009. Pp. xxvi + 166 P/b \$21.95
}

David M. Lovelace

Published online: 8 May 2010

(C) Springer Science+Business Media, LLC 2010

Keywords Owen · Huxley · Philosophy of science Ape brain debate $\cdot$ Humanistic perspective

In the years immediately following the 1859 publication of Darwin's Origin of Species (Darwin 1859), a disagreement over man's place in nature and his relationship to the great apes was debated between two iconic nineteenth-century scientists, Richard Owen and Thomas Henry Huxley. Though many readers will likely be familiar with the clash between Darwin's critics and defenders such as Huxley, who was famously sharpening his claws and beak in readiness, few are likely to be as conversant with the history and philosophy underlying the arguments. Christopher E. Cosans' Owen's Ape and Darwin's Bulldog: Beyond Darwinism and Creationism was published on the 150th anniversary of Mr. Darwin's Origin and tells a detailed story of the historical, philosophical, economic, and cultural stage upon which the "ape brain debate" between Owen and Huxley ensued.

Similar to both Huxley and Owen, Christopher Cosans has a firsthand perspective of the importance of anatomical dissection and its place in the study of the relationships between organisms; in fact he has gone so far as to reproduce the dissections that originally demonstrated the anatomical structures central to the ape brain debate. It is laudable that a philosopher of science is so well versed in

D. M. Lovelace $(\square)$

Department of Geoscience, University of Wisconsin-Madison,

1215 W Dayton St.,

Madison, WI 53706, USA

e-mail: lovelace@geology.wisc.edu the skills of the "dirty dissecting theatre." Ultimately, Cosans leads the reader through a maze of philosophical terminology and concepts all the while using the HuxleyOwen debate as a vehicle to demonstrate the differences between scientific materialism and the humanistic realist perspective and how they relate to modern science, ethics, and society.

Cosans begins by taking the reader on a journey through nineteenth-century Western philosophy of science with the parable of the "hippopotamus major" in Charles Kingsley's The Water-Babies (Kingsley 1863) as a tool to explain the differences between scientific and humanistic thinking, which in the end is the central theme of Owen's Ape.

In the first half of the book (chapters 2-4) the reader is immersed in the philosophical ideas that surround the anatomical discussions regarding the similarities and differences in the brains of ape and man. The anatomical observations that Owen published prior to Darwin's Origin highlight features that differentiate man from ape, placing him in a subclass of mammal well removed from an ape ancestor. In these chapters Cosans counters social constructivism critiques that suggest Owen's views were in opposition to social reform, exemplified primarily in the works of Adrian Desmond (1986, 1992). All the while Cosans clearly demonstrates how Owen dealt with the issue of race by using non-European specimens such as the crania of Papuans to typify man, providing strong support "that the difference between Papuan and adult ape skulls overshadows any difference between Papuans and Europeans" (pg. 52). Considering the broader context of how nineteenth-century biologists viewed the human races, Cosans summarizes Owen's view “that, compared to apes, 
the brains of the human races are quite similar" as an atypical opinion for the time (pg. 51).

The last half of the book is broken into several components. First, the reader is taken on a tangent (chapter five) to explore the role economic forces played in evolutionary thought as Darwin's Origin was making its debut in 1859. Cosans uses the works of Karl Marx and John Stuart Mill to reveal how these economists model materialistic and humanistic philosophies later to be represented by Huxley and Owen, respectively. The next two chapters deal with the publication of Origin of Species, values and society, and the reasoning behind Owen's rejection of what he considered the overly simplistic idea of natural selection. Cosans states that while "Owen agreed that evolution occurs, he argued that it occurs by more complicated means than those outlined in the Origin" (pg. xix). It is argued by Cosans that Owen supported the view that all of life, from its origins to its current diversities, is explainable through natural laws that have been ever present. Though Darwin demonstrated natural laws responsible for the passing of heritable information and natural selection of those traits, he did not extend the natural laws to explain the origins of life itself, rather he invoked God as the originator of life. Owen instead presumed God created the original natural laws and that life originated according to those laws. It is, however, unfortunate that this topic was not covered in more detailit would make a fascinating story in its own right.

It is not until the eighth chapter that the persona named in the latter half of the book's title, Darwin's Bulldog, really comes into play. Although Huxley is the other half of the argument, the majority of the book is dedicated to explaining Owen's positions and defense of his arguments. Huxley postulates that through objective, value free observations the scientist can discover unambiguous facts. He then proceeds to demonstrate observations of anatomical structures that suggest man should not be placed as a subclass of mammal, but rather that man belongs squarely within primates. Cosans continues with a discussion of the philosophical differences between Huxley and Owen and concludes that although Huxley had won the support of the scientific community of the time, he had not in fact directly refuted Owen's analysis that demonstrated differences in ape and human biology.

The final chapter of the book uses the debate between Huxley and Owen to illustrate how values can enter into the interpretations of scientific endeavors and provides exam- ples of value laden interpretations. The major thesis of Cosans' Owen's Ape and Darwin's Bulldog might be summed up as follows: "The humanistic approach to science, in contrast to those of materialism and social constructivism, allows for a consideration of values as part of conducting science from a human perspective" (pg. 142). In this manner the humanistic approach considers society, the individual, and values inherent to observations. According to Cosans, Owen, the consummate nineteenth-century anatomist, approached anatomy from a humanistic realist perspective. This perspective allowed Owen to "perceive the importance of the individual" and to "focus upon how organic structure emerges from developmental processes that come from within the individual organism" (pg. 143). In this light Owen might be seen as the precursor to a current trend in biology, the study of evolutionary development, or evo-devo (Amundson 2005).

In the end, Owen's Ape was an interesting voyage into Western philosophy, even if a rather strongly one-sided argument for a humanistic approach to science. As science becomes more and more value driven with focus (and funding) being placed on broad fields of study including global warming, ecological collapse in the face of overpopulation, and a necessity for the development of alternative energies, perspectives such as this provide a valuable tool to help illustrate the larger philosophical foundations essential to conduct responsible science. This book, however, is likely to be more frustrating than helpful to those seeking a treatise on evolutionary theory or even a historical story of the debate between Thomas Huxley and Richard Owen. Owen's Ape and Darwin's Bulldog introduces a brilliant, new and insightful perspective into the philosophy behind Richard Owen's methods and reasoning, but it is not an easy book for the uninitiated student of evolutionary theory.

\section{References}

Amundson Ron. The changing role of the embryo in evolutionary thought. Cambridge: Cambridge University Press; 2005.

Darwin Charles. On the origin of species by means of natural selection, or the preservation of favoured races in the struggle for life. London: John Murray; 1859.

Desmond AJ. Archetypes and ancestors: palaeontology in Victorian London, 1850-1875. Chicago: University of Chicago Press; 1986.

Desmond AJ. The politics of evolution: morphology, medicine, and reform in radical London. Chicago: University of Chicago Press; 1992.

Kingsley Charles. The water-babies. Oxford \& New York: Oxford University Press, 1995; 1863. 